\title{
Avaliação do aprendizado na produtividade em obras de montagens industriais eletromecânicas: abordagem por meio de dinâmica de sistemas
}

\author{
Antonio Fabio Guimarães Torres \\ antoniofabiog@bol.com.br \\ Wanyr Romero Ferreira \\ Professora do Programa de Mestrado da Faculdade Ietec \\ wanyr@terra.com.br
}

Mestre em Engenharia e Gestão de processos e sistemas pelo programa de Pós-graduação de FaculdadeIetec

Eduardo Trindade Bahia

mestre em Engenharia Agrícola pela Universidade Federal de Viçosa. Doutor em Ciencias del Mar - Universitat Politècnica de Catalunya - Barcelona Tech

etbahia@gmail.com

\section{processos}

Editor Científico: José Edson Lara

Organização Comitê Científico

Double Blind Review pelo SEER/OJS

Recebido em 06.08.2019

Aprovado em 20.12.2019 


\title{
Resumo
}

Contexto do estudo: a otimização da produção é o foco principal das grandes indústrias. Sendo assim, para aumentar a produtividade, o setor de montagens eletromecânicas precisa romper barreiras difíceis, como a falta de mão de obra com qualificações adequadas no local ou região da obra, e a disputa pelos melhores profissionais especializados no setor de infraestrutura.

Objetivo: estudar a influência do aprendizado da mão de obra na formação da memória de conhecimento e no desempenho da organização em obras de montagens eletromecânicas industriais.

Procedimento metodológico: desenvolveu-se um modelo de dinâmica de sistemas para simular o comportamento dinâmico da produção, da força do trabalho e da produtividade.

Resultados: os resultados mostraram que a transferência do aprendizado assim como o aprendizado adquirido, podem melhorar a produtividade, consequentemente os resultados esperados pela obra em questão, mostrando possibilidade de análise futura da tendência ao que poderá acontecer no quesito produtividade sobre a influência do aprendizado.

Palavras-chave: Dinâmica de Sistemas. Obras de Montagens Industriais Eletromecânicas. Aprendizado. Produtividade.

\section{Evaluation of learning in productivity in electromechanical industrial assembly works: system dynamics approch}

\begin{abstract}
Context: production optimization is the main focuso flarge industries, so in order to in crease productivity, the electromechanical assemblies sector needs to break through difficult barriers, such as the lackofskilled labor at the site orregion of the work, and the dispute by the best professional specialized in the infrastructure sector.

Objective: to study the influence of the learnin gof the work force on the formation of the memory of know ledge and the performance of the organization in works of industrial electromechanical assemblies.

Methodological procedure: for this, a system dynamics model was developed to simulate the dynamics behavior of production, labor force and productivity.

Results: the results showedthat the transfer of learning as well as the acquired learning can improve the productivity, consequently the expected results of the work in question, showing the possibility of future analysis of the tendency that can happen in the productivity question on the in fluence of learning.
\end{abstract}

Keywords: Systems Dynamics. Works of Industrial Electromechanical Mounts. Learning. Productivity.

\section{Evaluación del aprendizaje en productividad em trabajos de ensamblaje industrial electromecánico: enfoque de dinámica de sistemas}

\section{Resumen}

Contexto: la optimización de la producción es el foco principal de las grandes industrias, siendo así, para aumentar la productividad, el sector de montajes electromecánicos necesita romper 
barreras difíciles, como la falta de mano de obra con cualificación es adecuadas en el local o región de la obra, y la disputa por los mejores profesionales especializados en el sector de infraestructura.

Objetivo: estudiar la influencia del aprendizaje de la mano de obra en la formación de la memoria de conocimiento y en el desempeño de la organización en obras de montajes electromecánicos industriales.

Procedimiento metodológico: se desarrolló un modelo de dinámica de sistemas para simular el comportamiento dinámico de la producción, de la fuerza del trabajo y de la productividad. Resultados: los resultados mostraron que la transferencia del aprendizaje así como el aprendizaje adquirido, pueden mejorar la productividad, consecuentemente los resultados esperados por la obra en cuestión, mostrando posibilidad de análisis futuro de la tendencia a lo que podría ocurriren el aspecto productividad sobre la influencia del aprendizaje.

Palabras clave: Dinámica de Sistemas. Obras de Montaje Industrial Electromecánicas. Aprendizaje. Productividad.

\section{Introdução}

Ao longo da história das indústrias de montagens eletromecânicas, ocorreram diversas mudanças, desde os equipamentos às metodologias construtivas. Os recursos tecnológicos estão cada vez mais desenvolvidos e automatizados, mas a tecnologia ainda não é capaz de eliminar a peça chave de todo esse contexto industrial que é a mão de obra intensiva.

O sucesso de uma empresa pode ser atribuído a diversos fatores, como bons gestores, a estrutura de mercado, e não menos importante, os trabalhadores. A produtividade é um forte indicador de performance nas empresas de montagens de obras industriais. Atrelado a isso, alcançar ganhos de produtividade estão diretamente relacionados à adoção de melhores práticas e bom desempenho dos trabalhadores, e esses ganhos são os grandes desafios das empresas (Baitello, 2012).

No cenário nacional as corporações que atuam no setor de montagens eletromecânicas não fogem a esse objetivo de aumentar a produtividade, porém, enfrentam grandes desafios, e precisam romper barreiras difíceis, como a falta de mão de obra com as qualificações adequadas no local ou região da obra, e a disputa pelos melhores profissionais especializados no setor de infraestrutura. No entanto, pode haver ações que minimizem essas carências, principalmente as que dizem respeito ao conhecimento, muitas delas podem ser desenvolvidas pelas próprias empresas.

Segundo Martins \& Laugeni (2005), vários são os fatores que determinam a produtividade de uma empresa, merecendo destaque: i) relação capital e trabalho: indica o nível 
de investimento em máquinas, equipamentos e instalações em relação à mão de obra empregada; ii) a escassez de alguns recursos, como energia elétrica, iii) mudanças na mão de obra: os custos aumentam conforme sua qualificação; iv) inovação e tecnologia: o aumento da produtividade a médio e longo prazos indicam investimentos em pesquisas e desenvolvimento; v) restrições legais, por exemplo, ambientais; vi) fatores gerenciais: relacionados com a capacidade dos administradores de se empenharem em programas de melhoria de produtividade em suas empresas e; vii) qualidade de vida: muitas empresas procuram melhorar a qualidade de vida de seus funcionários visando aumento da produtividade.

Baitello (2012) desenvolveu um modelo de dinâmica de sistemas que simula o comportamento dinâmico da produção de um estaleiro com o objetivo de estudar a produtividade da empresa e garantir sua sustentabilidade, a partir do aprendizado. No setor de obras de montagens eletromecânicas, não se encontrou um estudo similar.

O administrador que tenha visão sistêmica, leva vantagem de imediato na análises relacionadas a produção, porque enxerga sempre o todo e as interações entre suas partes, conseguindo prever as possíveis consequências de suas decisões - impactos positivos e negativos, com o foco na falha dos sistemas, um erro no sistema ou de decisão, pode ocasionar grandes prejuízos as empresas (Paranhos Filho, 2007)

Assim, este trabalho busca, a partir do pensamento sistêmico, mostrar a influência do aprendizado da mão de obra e seu aparelhamento, na formação da memória de conhecimento e no desempenho da organização, analisando a relação desses elementos com as variações de produtividade em obras de montagens eletromecânicas industriais, de forma a auxiliar como ferramenta de trabalho aos gestores de empresas de montagens industriais eletromecânicas, no seu dia a dia, com intuito de agregação de valor ao negócio e ao empreendimento.

\section{Referencial Teórico}

\subsection{Obras de montagens Industriais Eletromecânicas}

Considerando competitividade empresarial um conjunto de ações na qual as entidades comerciais implantam com o objetivo de potencializar seus resultados e fazer com que sejam os mais importantes dentro do seu setor. A competitividade das empresas está diretamente relacionada à evolução da produtividade industrial. A abertura das relações comerciais brasileiras aos mercados mundiais, que ocorreu a partir dos anos 90, contribuiu imensamente para os ganhos tecnológicos e para a modernização dos processos produtivos, favorecendo assim uma reestruturação produtiva. Este fato promoveu uma interferência direta nas atividades 
industriais, e um setor industrial que teve sua produtividade destacada a partir deste processo de abertura foi a indústria de máquinas elétricas e de eletrônicos (Galeano; Wanderley, 2014).

Esta evolução da produtividade foi alavancada também pela competitividade comercial, devido aos projetos cada vez mais desafiadores no quesito prazo de implantação, exigindo das empresas estudos de metodologias construtivas e o trabalho de desenvolvimento do time de execução para atenderem estas demandas ousadas de prazo, devendo estas estar alinhadas a qualidade, particularidade técnica e a desempenho em segurança no trabalho.

A engenharia construtiva, na qual estão inseridas as obras de montagens industriais eletromecânicas, sempre foi em nosso país uma grande vertente do crescimento econômico nacional, desempenhando papel fundamental no desenvolvimento tecnológico e produtivo. $\mathrm{O}$ setor de montagem industrial é muito amplo incluindo, além de vários tipos de instalações em obras novas, projetos de reformas, expansão e manutenção. Segundo Fernandes (2005), a gestão dos serviços de engenharia possui papel relevante, pois é responsável pela integralização das diversas áreas que compõem o projeto, e buscam também otimizar os recursos na busca da melhoria dos índices de produtividade.

As obras mudam com as externalidades, ou seja, um mesmo tipo de obra assume valores diferentes quando executadas em locais diferentes, ou se executada no mesmo local em épocas diferentes do ano com mudanças climáticas drásticas. Por isso, a compreensão de todos os fatores envolvidos no projeto se torna algo importantíssimo, e que pode garantir o sucesso da obra (Ferreira, 2016). Atrasos em projetos, assim como alterações de seus custos, são desvios normais de acontecer em obras, o que requer alto nível de conhecimento e gerenciamento dos projetos.

Segundo Vargas (2009), as obras industriais requerem um alto padrão de planejamento e gerenciamento de projeto visto que, em geral, são trabalhos de grande porte, onde centenas de pequenos projetos estão ocorrendo concomitantemente e em disciplinas distintas, como obras civis, elétricas e mecânicas. Outro aspecto que remete à gestão dos empreendimentos como projetos é a sua interface nos setores da empresa, não apenas diretamente ligados na montagem propriamente dita. Em uma obra de montagem eletromecânica existe toda a gestão dos aspectos administrativos como: Segurança do Trabalho, Meio Ambiente, Recursos Humanos, Administração de Pessoal (Refeições, Alojamento, Ponto, etc), Logística, Medicina do Trabalho e tratativas entre as partes como Sindicatos e Sociedade em geral. 
A importância do capital intelectual como um dos principais fatores de agregação de valor para área de montagem eletromecânica no setor de projetos pode ser percebida fazendose um paralelo com a indústria. Nesta o aumento da produtividade é consequência da automatização e padronização de processos, utilizando cada vez menos pessoas, tendo em vista a intensificação do uso de tecnologias modernas e da automação. Por outro lado, na área de montagem eletromecânica, os recursos humanos representam de $40 \%$ a $60 \%$ dos custos totais (Almeida, 2009).

\subsection{Produtividade}

Os processos de gerenciamento empresarial sofreram mudanças ao longo do tempo. Ao passar a terceirizar mais serviços e dirigir o foco para seus produtos, as empresas perceberam que era preciso agregar tecnologia a seus produtos e serviços para permanecerem competitivas e com maior valor agregado, assim como voltar os esforços aos treinamentos comportamentais e motivacionais, visando despertar no trabalhador o espírito cooperativo (Felizardo, 2010). Toda essa evolução gira em torno de um só cerne, que é a produtividade, pois só assim é possível atingir a competitividade e a lucratividade.

A produtividade é um dos indicadores mais importantes para avaliar o desempenho dos sistemas econômicos e pode ser interpretado por dois parâmetros, macro e microeconômico. Segundo Andrade (2011), na visão microeconômica, a produtividade é um fator para dimensionar o nível de eficiência na utilização dos recursos. Se esses valores forem satisfatórios, indicam que os ganhos contínuos de produtividade podem ser um dos fatores que sustentam a competitividade da empresa no contexto econômico onde opera. Já em uma análise macroeconômica, a produtividade está diretamente relacionada e é um fator determinante do crescimento econômico de um país, visto que pode ser relacionada diretamente com o nível de bem-estar econômico da população.

Segundo Mussolini \& Teles (2010) os níveis de produtividade de uma economia podem ser entendidos como a análise da maneira com que os insumos (capital e trabalho em geral) são combinados na produção. Assim, é possível relacionar diretamente a quantidade de insumos ao aumento de produtividade e consequentemente ao aumento no produto. Este aumento de produtividade pode ocorrer associada ao progresso técnico, o que em termos de uma função de produção seria a utilização de tecnologias, ou em outra análise, ao aumento da eficiência econômica, dada pelo desempenho econômico mais eficiente. Tratando de uma ligação direta entre tecnologia e eficiência econômica, os autores mostram que os mesmos impactam 
diretamente na produtividade, e que uma economia que está distante dessa fronteira tecnológica pode ser ineficiente, afetando a produtividade.

A produtividade pode ser avaliada em diversos aspectos e possui diversos indicadores que permitem essa análise. Um destes indicadores é a eficiência do trabalho em cada lugar, ou seja, o quanto o trabalho realizado em determinada função e lugar está sendo importante e relevante para a produtividade sistêmica (Costas, 2014). Não se trata apenas de entender o processo produtivo, é possível através das análises de produtividade desenvolver estratégias inovadoras para a gestão de projetos.

O desafio das empresas do setor de montagens é fazer com que a mão de obra tenha um desempenho melhor, mais especificamente quando se trata de obras de montagens industriais, pois, cada obra acaba acarretando situações cíclicas, como curva de aprendizagem (uma obra sempre é diferente da outra), cultura local da mão de obra (até o tipo de alimentação influencia no comportamento das pessoas), e tempo para aplicação de treinamentos, entendimento do ambiente por parte da empresa, salários e benefícios. Até mesmo se a obra terá ou não horas extras pode ser um fator contribuinte para seu sucesso ou não.

O cálculo da produtividade pode ser parcial ou total, sendo que o parcial é mais utilizado, pois busca relacionar o comportamento da produção com o fator trabalho e o fator capital, sendo mais comum o cálculo relacionado ao trabalho, para entender a real contribuição do fator mão de obra com a produtividade (Andrade, 2011).

A quantificação da produtividade parcial pode ser relacionada com o fator trabalho, e é representada pela equação:

$$
\text { Produtividade }=\frac{\text { Quantidadedoproduto }}{\text { Quantidadedeinsumotrabalho }}
$$

ou pode ser relacionada com o fator capital:

$$
\text { Produtividade }=\frac{\text { Quantidadedoproduto }}{\text { Quantidadedeinsumocapital }}
$$

A equação 1 é a mais utilizada para entender a real contribuição do fator mão de obra com a produtividade (ANDRADE, 2011). As equações 1 e 2 permitem relacionar o comportamento da produção com o comportamento de apenas um dos fatores de produção utilizados, e o quanto estes fatores analisados isoladamente podem influenciar na produtividade. Os dados envolvidos tanto no cálculo parcial quanto total, são de difícil obtenção, passando muitas vezes por suposições de valores, o que pode gerar inverdades nos resultados, visto que 
se faz uma estimativa do fator capital e do fator mão de obra (o nível de qualificação varia ao longo do tempo) (Andrade, 2011).

No outro extremo encontra-se a produtividade total que tem a pretensão de indicar a eficiência com que a economia a totalidade de seus recursos para gera produto, desta forma avaliaria um contexto apenas econômico. (De Negrini; Cavalcante, 2015)

Empresas de montagens, muitas vezes, possuem seu banco de dados próprio sobre a produtividade esperada, de acordo com obras já executadas. Estes dados são necessários para a composição dos orçamentos e para a geração dos histogramas do empreendimento. Durante o empreendimento é possível analisar por meio de softwares específicos, o comportamento da produtividade esperada. Estes mecanismos são desenvolvidos e utilizados pelas empresas para análise e validação das ações sobre o que foi previsto, e o que está acontecendo de fato. Sendo a produtividade mutável, serve como indicador se o empreendimento vai ter sucesso ou não, uma vez que a produtividade estando baixa, por consequência não serão atendidos os prazos, o custo irá aumentar e o fracasso é iminente.

\subsection{Qualificação e aprendizado nas organizações - Produtividade e Mão de obra}

Historicamente o setor de obras de montagens esteve estagnado entre os anos 80 e 90, quando as empresas de montagens eram atrasadas e o crescimento bastante restrito, os investimentos em maquinários sofria com os valores altos de impostos de importação e o crescimento econômico era inexpressivo. Todos estes fatos fizeram com que as empresas desenvolvessem internamente suas técnicas de montagens, seus próprios manuais de procedimentos, e os conhecimentos técnicos não eram compartilhados, pois eram vistos como uma ameaça competitiva. Eram raras as publicações sobre montagens e o conhecimento era tratado como segredo (Pinho, 2008).

Segundo Felizardo (2010) qualificações são os conhecimentos específicos que o trabalhador tem sobre determinados processos produtivos e máquinas operatrizes. É possível um entendimento mais amplo do termo qualificação, que abrange o sentido de relação social entre os agentes, que envolve a propriedade, significado e uso dos conhecimentos, saberes, competências e habilidades necessárias a uma profissão. A importância da qualificação é inerente ao processo, e precisa ser valorizada e ganhar destaque no que se refere à obtenção de níveis ideais de produtividade. 
Havia grandes problemas em relação à qualidade dos serviços, faltavam certificações das empresas e dos profissionais de mão de obra de montagem, não havia uma padronização com um nível de excelência tanto nos procedimentos administrativos e gerenciais quanto nas áreas técnicas dos projetos (Pinho, 2008). A mudança dessa postura pode ser percebida na Figura 1, que apresenta a distribuição dos trabalhadores da construção civil nos anos de 2003 e 2009 no Brasil, por nível de escolaridade. Observa-se que o grupo de trabalhadores com ensino superior completo se manteve o mesmo. Já o grupo de trabalhadores com ensino médio subiu de $14 \%$ para $25 \%$, não necessariamente alocado em área técnica, que seria melhor aproveitado na indústria de montagem industrial.

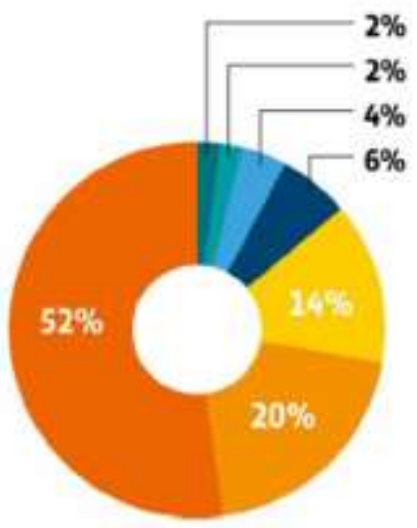

2003

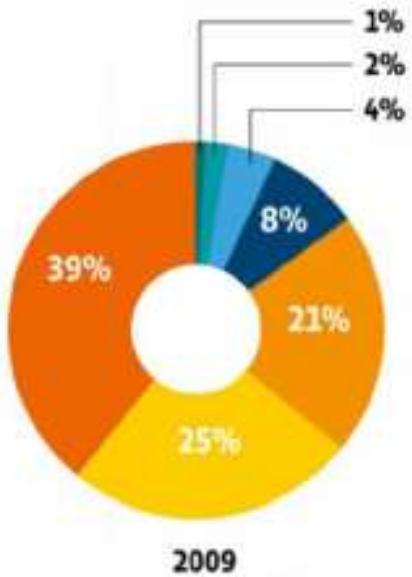

2009
Analfabeto

Fundamental completo

Fundamental incompleto

Médio completo

Médio incompleto

Superior completo ou Pós

Superior incompleto

Figura 1. Grau de instrução do trabalhador formal da construção: 2003 e 2009. Fonte: RAIS (Ministério do Trabalho e Emprego) CBIC - (2017).

As empresas de obras de montagem industrial eletromecânicas, em geral, precisam da mão de obra local para desenvolver suas atividades e, com isso, muitas vezes se tornam parceiras dos governos locais apoiando iniciativas na área de educação. Baitello (2012) avalia como de suma importância, a garantia da qualidade da formação, mas não menos importante, difundir os valores da organização e fortalecer o vínculo com a força de trabalho, o que pode influenciar na competitividade de uma empresa. Este tipo de ação se torna uma estratégia que favorece tanto o trabalhador, quanto a empresa, que consegue mão de obra mais capacitada e profissionais mais comprometidos com a empresa. Esta deve ficar atenta ao "timing”, para não deixar de focar em qualificação de seu quadro apenas quando já tiver sofrendo o impacto da ausência dela.

Na busca de reverter este quadro de estagnação e falta de qualidade, as empresas buscam cada vez mais a qualificação da mão de obra, implementando uma nova cultura empresarial, 
com tendência a exigir cada vez mais uma maior escolaridade dos seus profissionais, mudando o perfil do trabalhador brasileiro. Busca-se referência nos países mais desenvolvidos, onde o ensino médio é o nível básico para se chamar alguém de profissional em qualquer cargo, o que mostra que o nível de escolaridade reflete diretamente nos índices de produtividade da mão de obra e na respectiva remuneração (Pinho, 2008).

A taxa de aprendizado nas organizações é algo relevante e varia consideravelmente de organização para organização. As taxas de crescimento da organização muitas vezes são analisadas em dois parâmetros: a taxa de crescimento da produtividade pelo aumento da produção liquida, e aos ganhos de produtividade esperados da aprendizagem (Argote; Epple, 1990).

\subsection{Dinâmica de sistemas}

As obras de montagens industriais eletromecânicas têm ficado em um patamar ruim em comparação a outras indústrias quando se analisa a relação eficiência e eficácia. A utilização de ferramentas de análise da dinâmica de sistemas e a simulação de cenários podem ser úteis para a busca de parâmetros que podem auxiliar no aumento de produtividade. E quanto maior a eficiência e a eficácia, menor o tempo para executar o serviço e consequentemente menor os custos totais (Gonçalves; Figueiredo, 2015).

Com o orçamento de uma obra o contratante tem em mãos o instrumento de verificação sobre a técnica e a administração do prestador de serviço. Para tal, é preciso que seja feita a estimativa orçamentária de custo com total confiabilidade, para que se tenha uma previsão dos gastos com o empreendimento. Como existem fatores que influenciam nesses orçamentos, o cenário virtual, criado através da dinâmica de sistemas permite uma maior aproximação e conhecimento das possibilidades (Ferreira, 2016).

Quando se trata da indústria, considera-se sistema como o conjunto de áreas, cada uma desempenhando um papel fundamental dentro da indústria, sendo estas áreas: Estratégia e Gerenciamento, Marketing, Suprimentos, Recursos Humanos, Engenharia, Planejamento de produção e Produção. A indústria de montagem eletromecânica tem suas peculiaridades, mas também possui estas áreas compondo seu cenário, portanto é importante conhecer detalhes e fazer uma avaliação ponderada desses campos de concentração. Uma avaliação ponderada dos dados sobre o desempenho dessas áreas permite um melhor entendimento sobre as práticas adotadas pela organização, abre caminhos para adoção de melhores estratégias na busca de uma 
melhor produtividade, possibilitando que as empresas superem as dificuldades operacionais e garantem sua competitividade produtiva (Baitello, 2012).

$\mathrm{Na}$ busca da melhoria contínua do desempenho da empresa e da performance profissional, o pensamento sistêmico ajuda a garantir uma compreensão do "todo" e está intimamente ligado ao aprendizado nas organizações. Para essa análise, Senge (1990) estabelece a importância do entendimento de cinco vertentes: pensamento sistêmico - a quinta disciplina, domínio pessoal, modelos mentais, visão compartilhada e aprendizado em equipe que se complementam. É possível entender esse comportamento dinâmico associado ao aprendizado através de instrumentos bastante precisos e sofisticados, como por exemplo, a utilização de softwares computacionais.

A curva de aprendizado é um instrumento que permite entender o progresso do processo de fabricação, assim como a análise de operações e estimativas de custos, a aprendizagem no contexto do gerenciamento de operações, refere-se à produtividade obtida a partir da repetição de uma operação, pois já se foi constatado que o desempenho humano melhora com o reforço ou repetições frequentes, reduzindo assim o tempo do processo, melhorando assim a produtividade. Os dados conseguidos através de uma curva de aprendizado permitem que essa curva sirva como ferramenta preditiva para obter estimativas de tempo e custos em um projeto (Badiru, 1991).

A estrutura das curvas de aprendizado passando por uma modelagem através da Dinâmica de sistemas resulta em um diagrama causal. As relações causais indicam que o efeito do aprendizado é decorrente da experiência e de uma fração $F$ chamada de intensidade do aprendizado que é a melhoria obtida cada vez que a experiência acumulada é dobrada. A Figura 2 mostra as grandezas envolvidas na composição de uma curva de aprendizado (Baitello, 2012). O efeito do aprendizado pode ser calculado por:

$$
\text { Efeito do aprendizado }=\left(\frac{\text { Experiência Acumulada }}{\text { Experiência Inicial }}\right)^{C}
$$

em que:

$C=\operatorname{Ln}\left(\frac{\operatorname{Ln}(1-F)}{\operatorname{Ln}(2)}\right)=$ Índice da curva de Aprendizado

$F=$ Intensidade do Aprendizado 


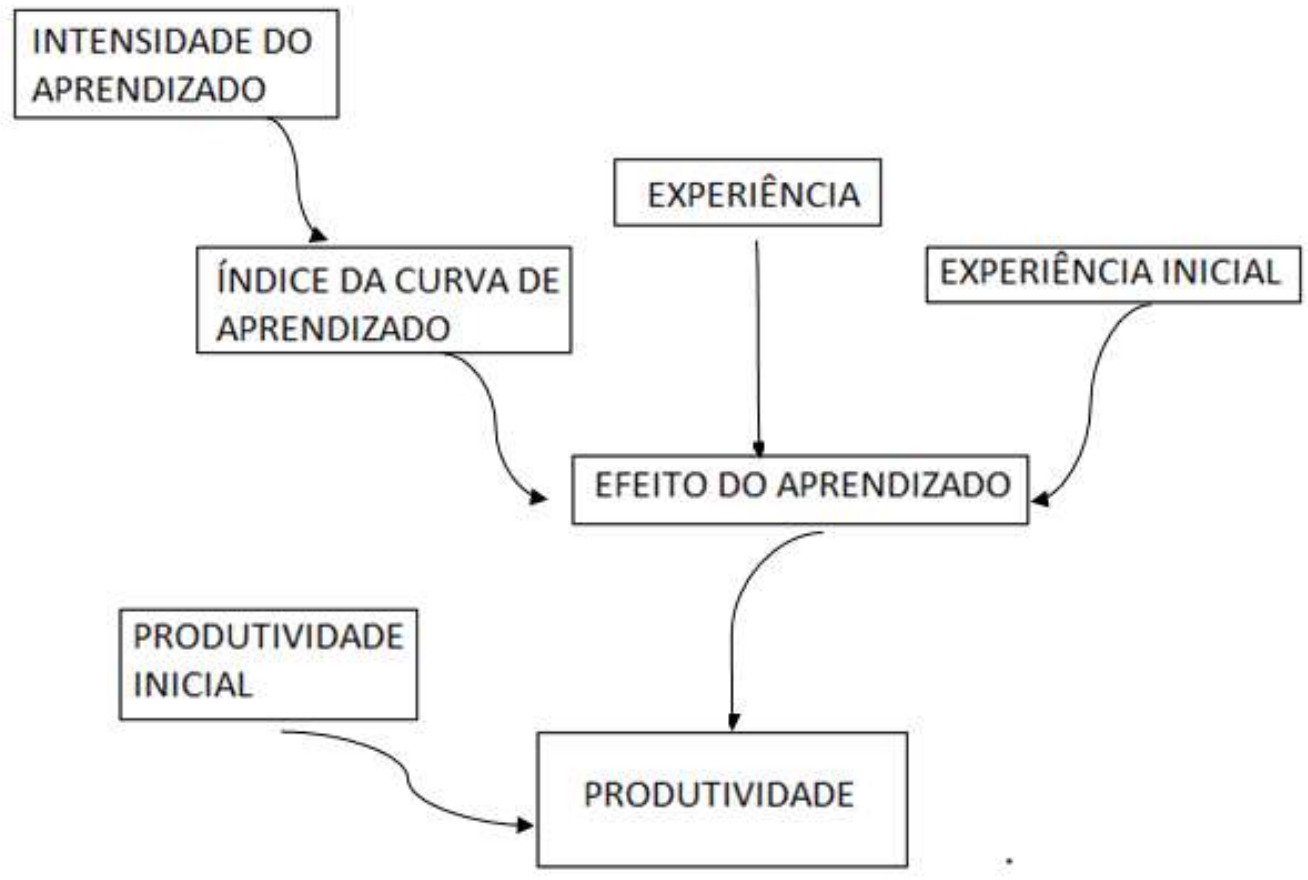

Figura 2. Estrutura de uma curva de aprendizado.

Fonte: Adaptado de Baitello (2012).

Pode-se medir a experiência acumulada tanto em função do número de unidades produzidas quanto pela quantidade de horas trabalhadas. Em obras industriais, ela pode ser medida pelas horas trabalhadas produtivas, o que irá, através da curva de aprendizado, demonstrar que o aumento da experiência deverá resultar na consolidação de boas práticas, permitindo uma avaliação sistêmica do comportamento dinâmico do aprendizado na produção (Baitello, 2012). A intensidade do aprendizado corresponde ao coeficiente que define a força dos ganhos do aprendizado, ou seja, quais as vantagens o aprendizado acarreta para a empresa. Porém, saber apenas isso não é suficiente, é preciso entender quais fatores influenciam a intensidade do aprendizado.

O processo de modelagem trazido por Baitello (2012) teve sua estrutura baseada no trabalho proposto por Sterman, no livro Business Dynamics: Systems thinkingandmodeling for acomplex world. Este modelo de processo é exposto na Figura 3. 

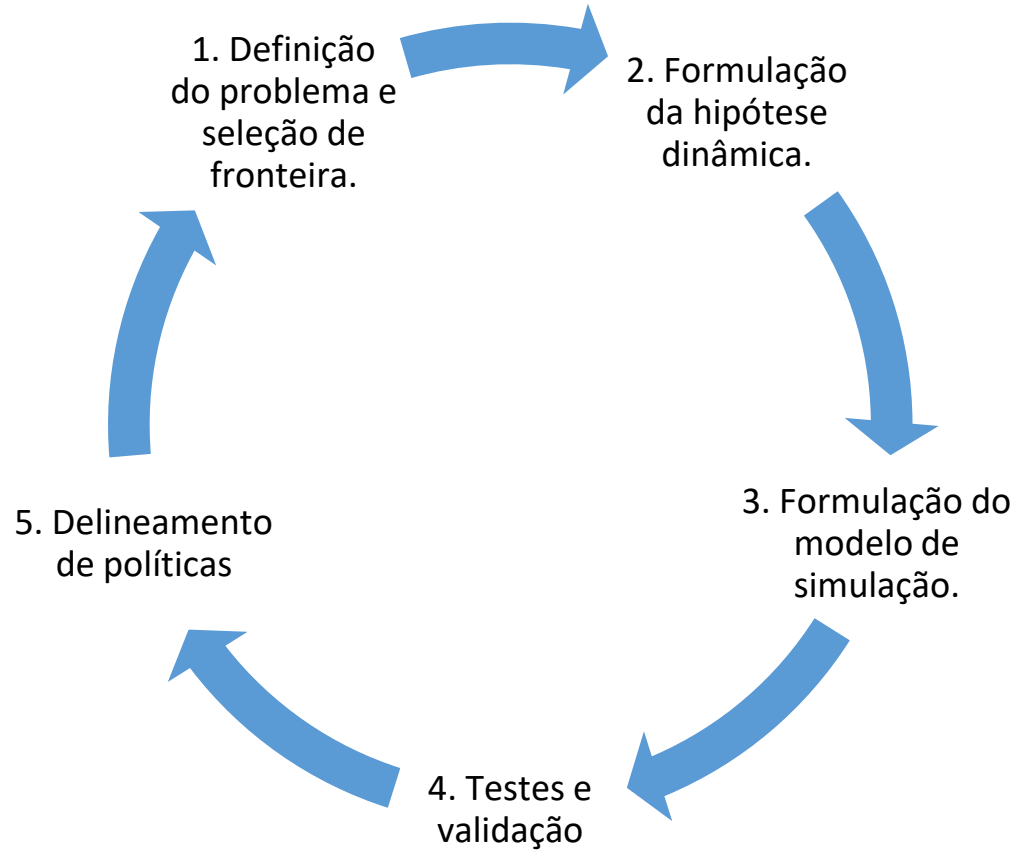

5. Delineamento de políticas

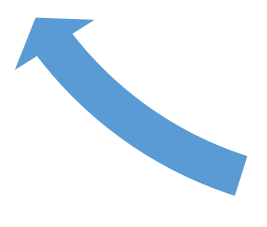
validação

Figura 3. Processo de modelagem. Fonte: Baitello, 2012, p.58.

Esta estrutura permite verificar que a modelagem é uma prática que, através de cada simulação, acumula experiência virtual e gera aprendizado sobre o mundo real. É uma verdadeira arma de gerar conhecimento para o modelador ou utilizador.

Para este estudo, será feito um modelo de simulação que se adeque tanto ao comportamento indesejado quanto ao desempenho histórico de uma obra de montagem industrial eletromecânica, e através do conhecimento sistêmico disponível na Dinâmica de Sistema, serão estudadas políticas que favoreçam o equilíbrio entre o aprendizado da força de trabalho e o aprendizado da corporação envolvida.

Esta estrutura permite verificar que a modelagem é uma prática que, através de cada simulação, acumula experiência virtual e gera aprendizado sobre o mundo real. É uma verdadeira arma de gerar conhecimento para o modelador ou utilizador.

Para este estudo, será feito um modelo de simulação que se adeque tanto ao comportamento indesejado quanto ao desempenho histórico de uma obra de montagem industrial eletromecânica, e através do conhecimento sistêmico disponível na Dinâmica de Sistema, serão estudadas políticas que favoreçam o equilíbrio entre o aprendizado da força de trabalho e o aprendizado da corporação envolvida. 


\subsection{Iterações do Processo de Modelagem}

Como o processo de modelagem é algo complexo, iterativo e gradual, à medida que se inicia um modelo de dinâmica de sistemas, novos elementos podem ser inseridos ou retirados, permitindo que relações sejam estabelecidas e descobertas ao longo da modelagem, fazendo com que o modelo evolua. Não é possível atingir um modelo perfeito, pois se assim fosse, seriam altamente complexos, o que os aproximariam demasiadamente do caso real de tal forma que os tornariam inúteis. Sendo assim, buscou-se manter iterações que representassem o caso real, mas que ao mesmo tempo fossem simples e com qualidade suficiente para atingir resultados positivos que pudessem ser analisados e comparados com dados históricos para validação do entendimento.

\subsection{Formulação da Hipótese Dinâmica}

Para descrever a hipótese dinâmica foram realizados os testes de validação do modelo para verificar a sua aderência à hipótese dinâmica e ao comportamento real das Obras de Montagens Eletromecânicas.

O foco da importância do Aprendizado em Obras de Montagens eletromecânicas é a Produtividade, ou seja, qual a real interferência do aprendizado na produtividade da obra. Para entender melhor essa relação foi levantada a hipótese mostrada na Figura 4, que traz em detalhes como seria a interação entre os fatores envolvidos no processo de aprendizagem e a produtividade. 


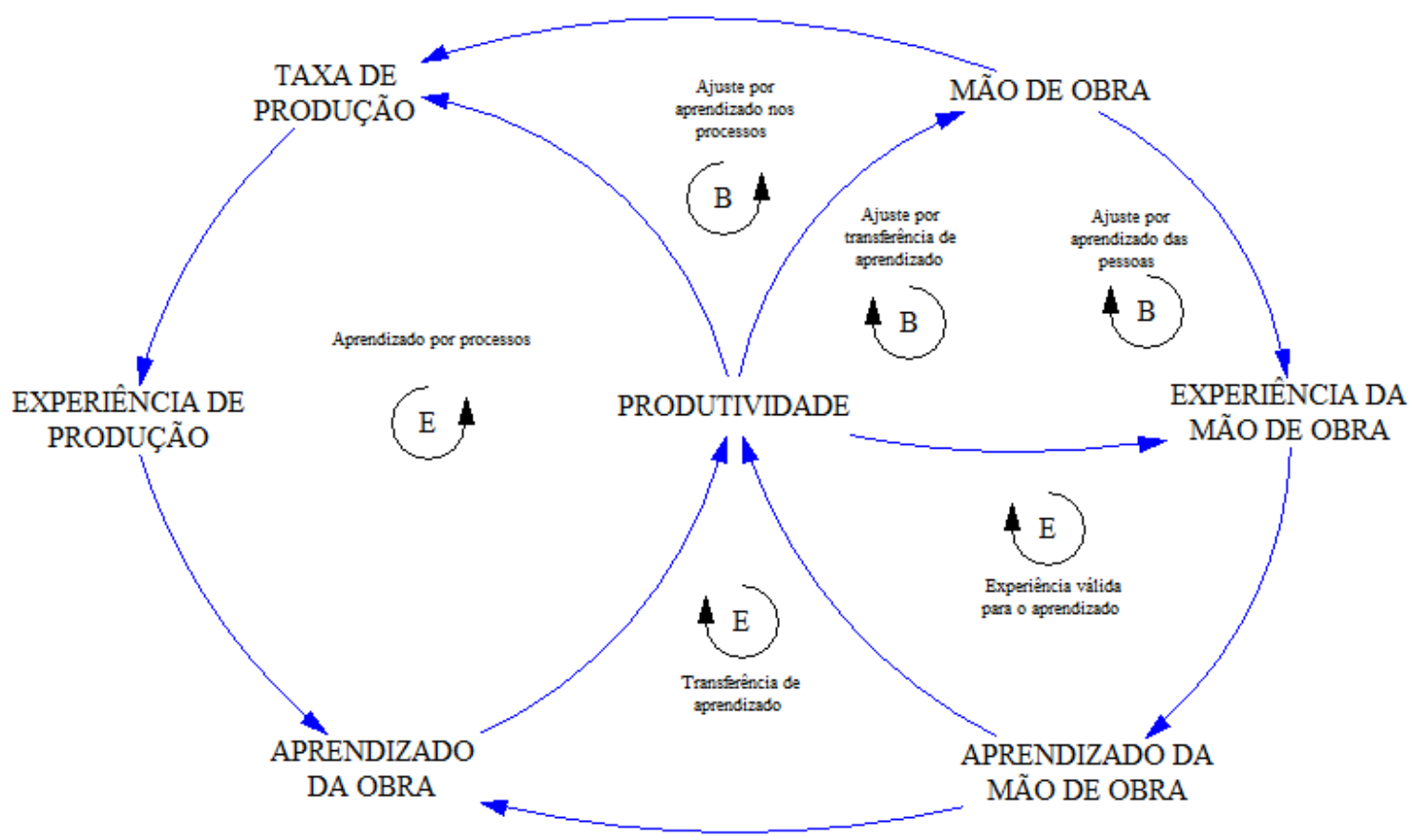

Figura 4. Diagrama da Hipótese Dinâmica Fonte: Elaborado pelos autores

Como a produtividade é uma variável mutável ao longo do tempo, o Aprendizado seja da Mão de Obra ou da Produção, influenciam diretamente na Produtividade. Sendo assim é preciso entender a composição destes aprendizados e consequentemente qual a parcela de interferência na Produtividade.

O modelo foi desenvolvido no ambiente do Vensim ${ }_{\circledast}$ na versão para uso acadêmico. $\mathrm{O}$ $V_{\text {Vensim }}{ }_{\circledast}$ é um programa bastante didático e funcional que permite ao usuário acessar, com facilidade, todos os detalhes da formulação do modelo. Estes detalhes são mostrados nos anexos.

O modelo formulado foi pensando a partir do Diagrama de Hipótese Dinâmica mostrado anteriormente na Figura 4. A partir deste diagrama pode-se elencar os elementos chave que interferem diretamente nas análises, sendo eles o Contrato, a Taxa de Produtividade Real e a Produtividade.

A partir da obtenção da Experiência da Mão de Obra, é possível chegar ao último esquema de modelagem, o da Produtividade, baseado no subsistema de Aprendizado, mostrado na Figura 5 . 


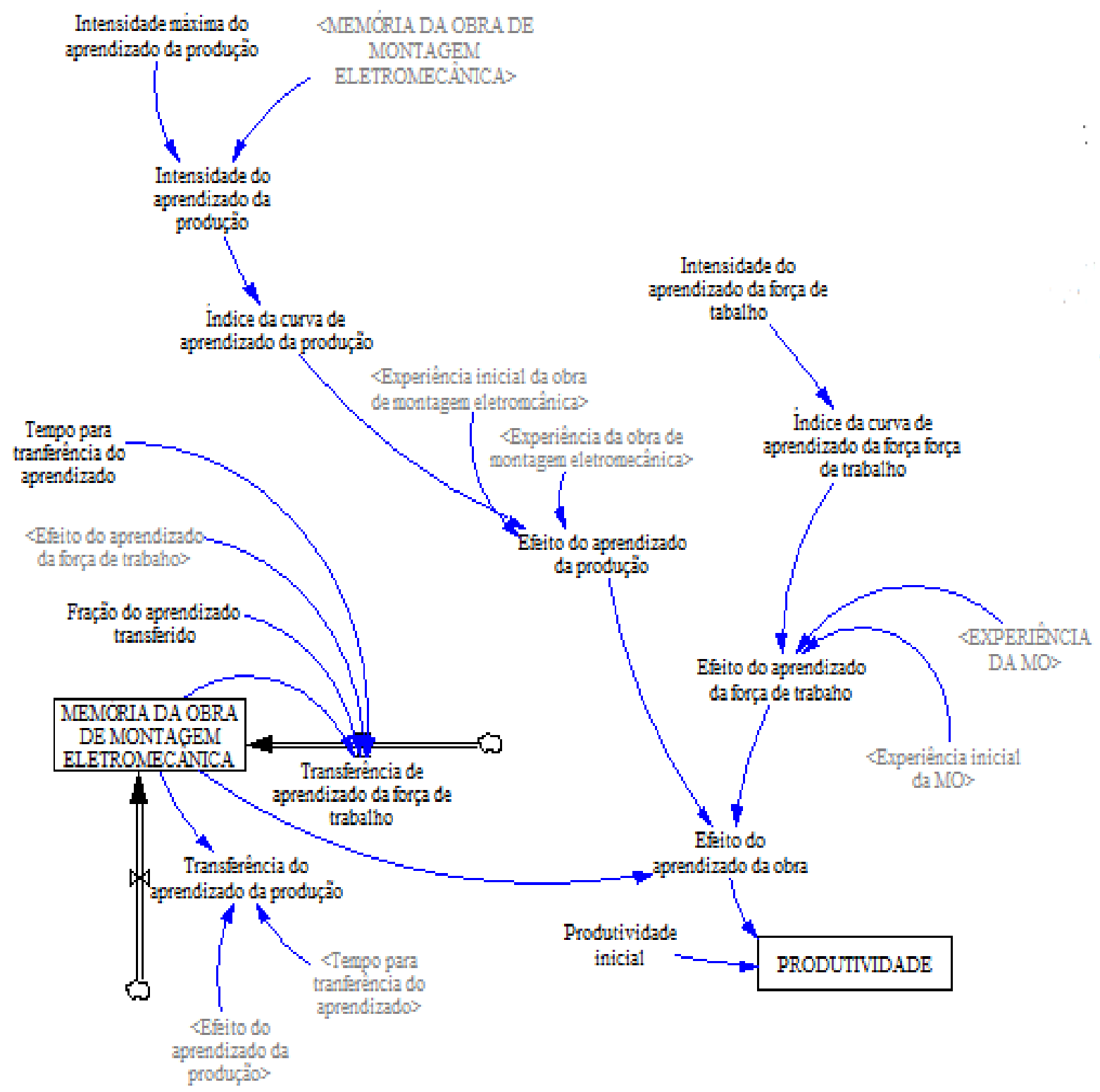

Figura 5. Modelagem da Produtividade a partir da Memória da Obra Fonte: Elaborado pelos autores

Todo o aprendizado, seja ele oriundo da força de trabalho ou da produção, é transferido durante as operações em uma Obra de Montagem Eletromecânica, sendo assim todo esse aprendizado é armazenado na forma de Memória da Obra. A modelagem apresentada na Figura5 tem o intuito de elucidar a interferência da Memória da Obra, ou seja, do aprendizado armazenado, na Produtividade. 


\section{Resultados e discussões}

A validação é a comparação dos resultados alcançados pelo estudo através da concordância do modelo com o sistema real. É realizada no intuito de confirmar ou não que a modelagem feita foi capaz de replicar o comportamento de uma obra real, conferindo assim credibilidade no uso do modelo para simular políticas, contribuir para as tomadas de decisões, sempre no caminho da melhoria do sistema.

O processo de validação por meio das simulações estimulou a evolução crescente das análises, permitindo a percepção de questões que não seriam observadas de outra forma.

Algumas variáveis chaves foram escolhidas como sendo premissas para o entendimento e calibração do sistema: Contrato, Mão de Obra Inicial e a Produtividade Inicial, estas escolhas foram devido a serem informações que temos condição de previsibilidade antecipada:

Contrato - A mensuração do peso em toneladas é possível com base nos levantamentos de projeto, considerando um tempo determinado podemos conseguir um volume por mês em toneladas;

Mão de obra Inicial - Com base nos recursos disponíveis e projeção de tempo pode-se determinar qual seria o start de mão de obra para a obra;

Produtividade Inicial - Com base em banco de dados ou mesmo em expectativa pode-se estimar a quantidade de hh/t esperada;

Essas variáveis serão as variáveis controladas. Foram utilizados dados de referência retirados de obras reais, que permitirão determinar o comportamento do sistema como um todo, sendo o período pré-determinado de 18 meses, simulando uma obra de grande porte.

Em Obra de Montagem Eletromecânica a Produção WIP (Wok in Progress) e a Mão de obra possuem seu ápice em torno do 3 mês, e se estabilizam concomitantemente no 5 mês. Apesar dessa estabilidade, o Orçamento em relação ao consumo de HH (Homem/Hora) por mês aumenta linearmente, porém utilizando a mão de obra já contratada, visto que a taxa de contratação reduz drasticamente a partir do terceiro mês, como também se estabilizam as taxas de turn-over, mostrando que a partir deste ponto já existe uma estabilidade no contrato no que tange mão de obra, já aconteceu o filtro natural de adaptação e consolidação de aprendizado com o escopo.

A Tabela 1 e a série de gráficos a seguir, servem como exemplo dentre todas as análises e casos propostos, mostram as tendências observadas em relação ao aprendizado, e de como se 
dá o comportamento das curvas oriundas da análise de transferência deste aprendizado em função do tempo.

Tabela 1

Variáveis de Contorno para as simulações dos casos 1 a 3.

\begin{tabular}{ccccc}
\hline Variável & \multicolumn{3}{c}{ Valor da Variável } & Grandeza da Variável \\
\hline & Caso 1 & Caso 2 & Caso 3 & \\
\hline Contrato & 10000 & 20000 & 30000 & Toneladas/Mês \\
\hline Mão de Obra Inicial & 500 & 500 & 500 & Pessoas \\
\hline Produtividade Inicial & 120 & 100 & 80 & HH/Tonelada \\
\hline
\end{tabular}

Fonte: Elaborado pelos Autores

Os resultados para o Caso 1 são apresentados nas Figuras 6 (Comportamento do Orçamento, Mão de obra e Produção WIP ao longo do tempo), 7 (Memória da Obra, Experiência e Mão de obra em função do tempo). 

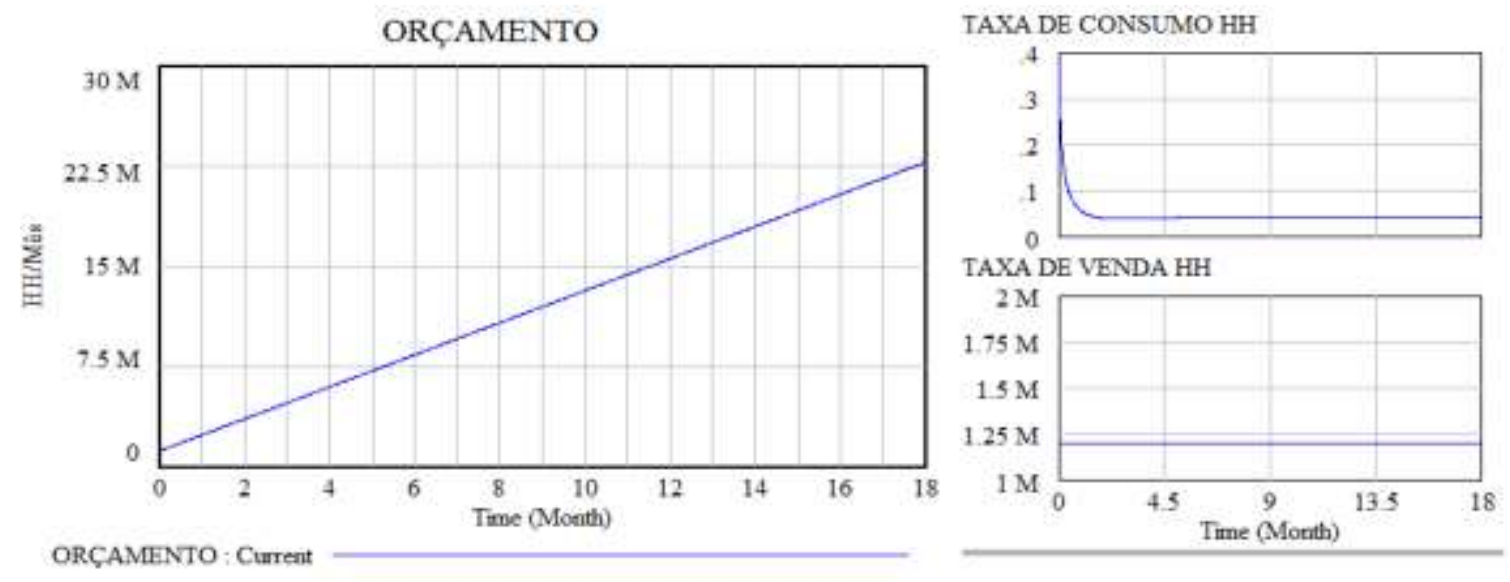

ORÇAMENTO : Current
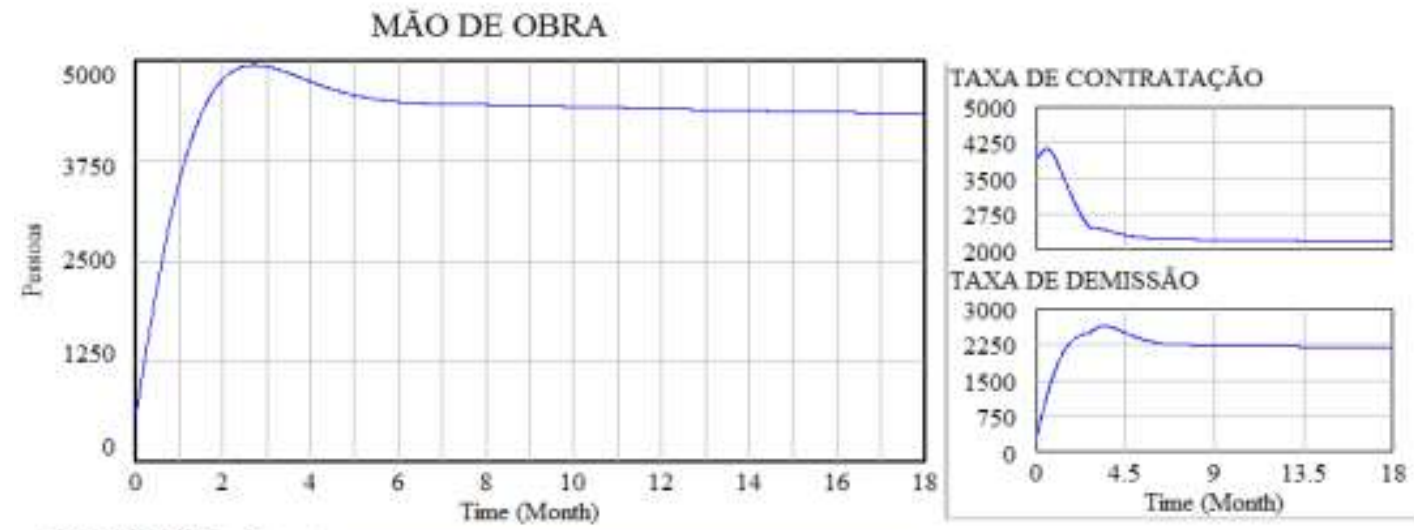

MẢO DE OBRA : Current $\frac{}{\text { PRODUÇĀO WIP }}$
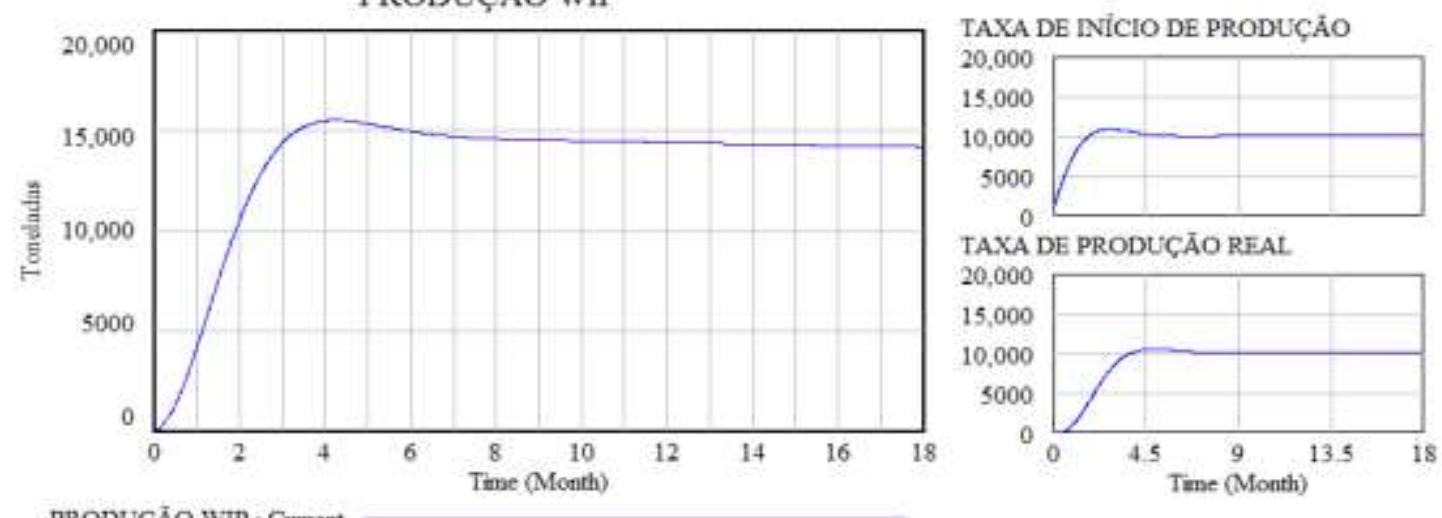

PRODUÇĀO WIP : Current

Figura 6. Orçamento, Mão de Obra e Produção WIP em função do tempo. Validação da Hipótese Dinâmica - Caso 1

Fonte: Elaborado pelos autores 
Memória da obra em relação à transferência de aprendizado

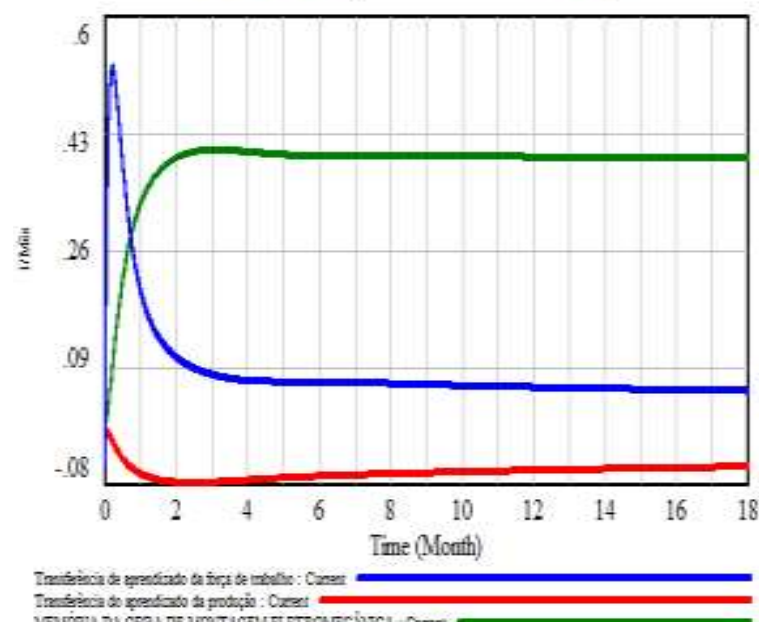

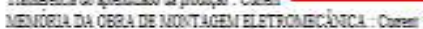

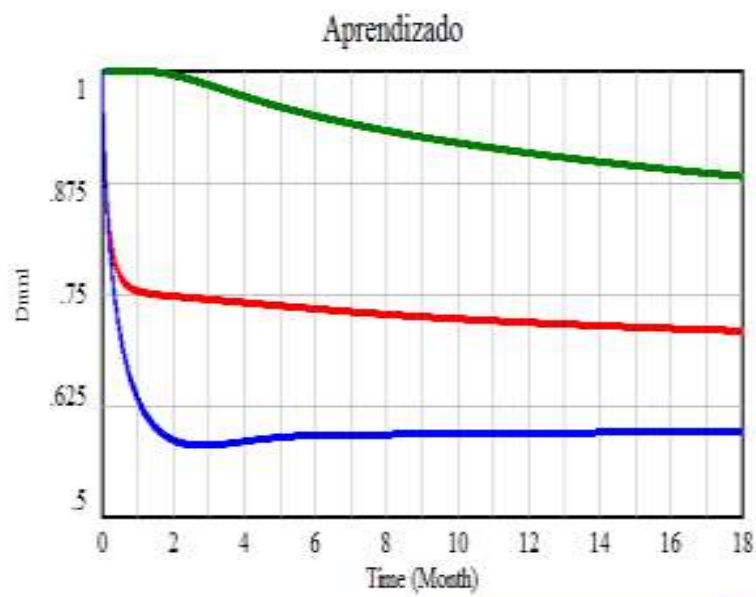

Eferto do aprendrado da força de trabaho: Corrent

Eferto do aprendrado da sbra: Cument -

Efeito do arrendhado da groduçào: Current

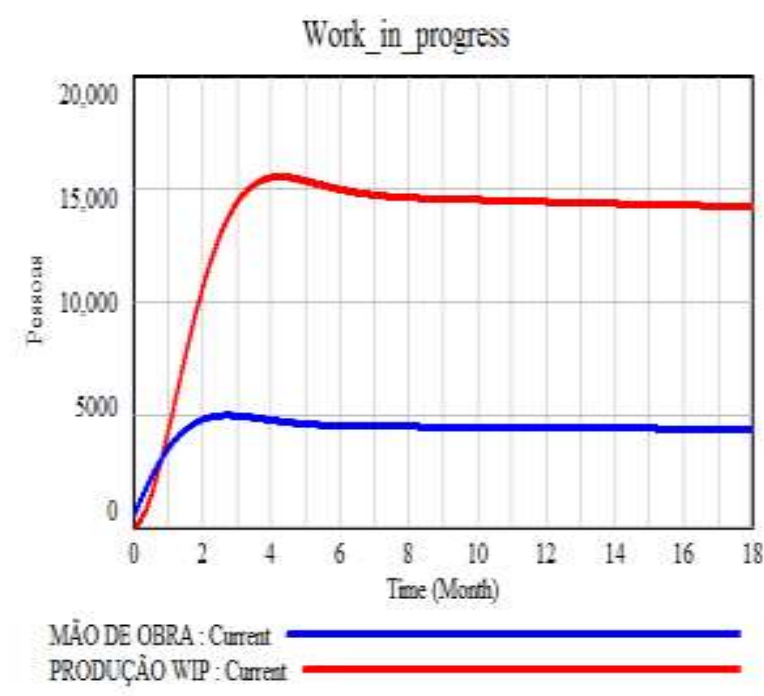

MÃODE OBRA : Current PRODUÇȦO WTP : Current

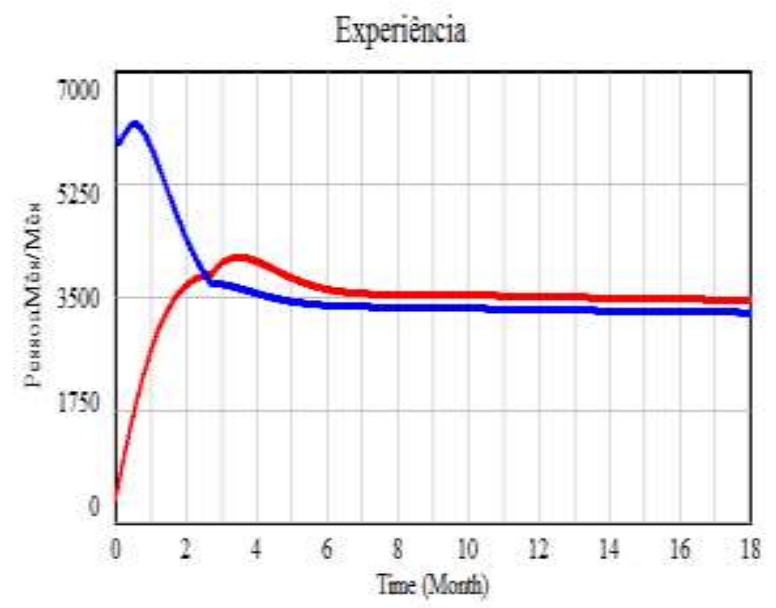

Ganho de expenithcia por contrataçà̃o : Current Perda de expeniencia por demissào: Current

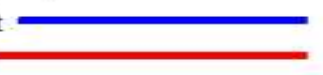

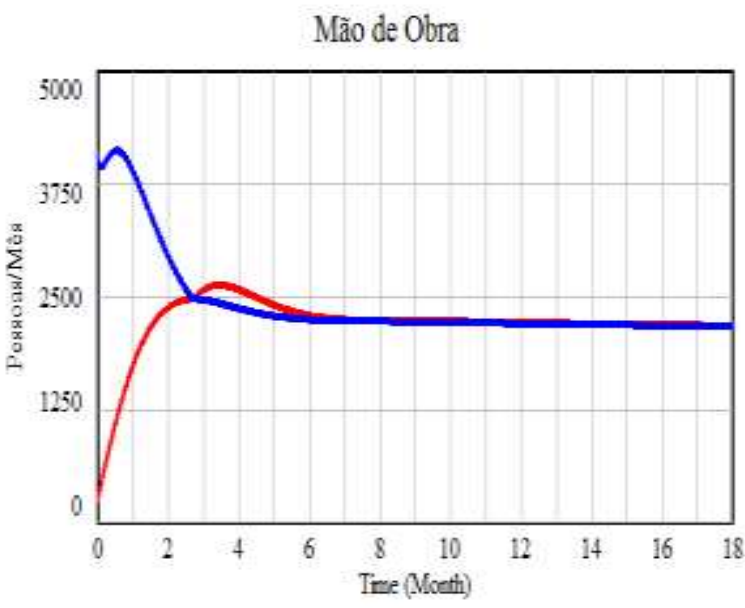

TAXA DE CONTRATACC̃O : Cument

TAXA DE DEMISSÃO : Current

Figura 7. Memória da Obra, Experiência e Mão de obra em função do tempo. Resultados comparativos - Caso 1

Fonte: Elaborado pelos autores 
$\mathrm{Na}$ verificação dos gráficos obtidos na simulação, percebe-se que a memória do aprendizado da empresa cresce ao longo do tempo, outra observação é que a memória do aprendizado na obra se estabiliza a partir do quarto mês, e o mais importante é que a produtividade melhora, com um gasto de $\mathrm{HH}$ menor por tonelada produzida. Todas essas observações remetem à conclusão de que a transferência de aprendizado é um contribuinte importante na performance da Obra de Montagem Industrial Eletromecânica. Interessante a observação que a transferência de aprendizado se estabiliza à medida que o turn-over diminui.

Assim para se manter essa estabilidade no consumo de HH para a realização das mesmas operações ao longo de uma obra é preciso valorizar o funcionário, permitir a reciclagem dos conceitos envolvidos, pode-se inserir medidores de desempenho que permitam melhores análises relativas ao conhecimento.

Comparando os resultados gerados em vários cenários rodados no programa, fica claro que mesmo quando se aumenta as quantidades de Contrato e alterando os valores de Produtividade Inicial, o desafio de se obter um melhor resultado relativo à Produtividade é atingido. Os resultados apresentam o mesmo aspecto, ou seja, o aprendizado é trocado mesmo com quantidades maiores de pessoas. Outro ponto importante pode ser observado em comparação com casos reais: como a obra de montagem eletromecânica geralmente é um novo projeto, a partir do momento em que os envolvidos conseguem dominar o escopo do trabalho a Transferência do Aprendizado logo se estabiliza, com melhora da Produtividade, trazendo a observação de que no caso de Obra de Montagens Industriais este conhecimento deve e tem de ser rápido para garantia e melhora da performance.

\section{Conclusões}

Uma obra de montagem eletromecânica é um empreendimento muito complexo e cheio de variáveis que podem ser norteadoras de sucesso e insucesso, sendo que os resultados são convertidos em ações diretas no gerenciamento do negócio. Este trabalho buscou desenvolver uma ferramenta de análise de dados que contribuísse para a melhoria dos resultados de Obras de Montagens Industriais Eletromecânicas, para auxiliar nas decisões gerenciais. O modelo desenvolvido pode ser utilizado em diversos momentos, seja durante a fase de orçamento, na análise de riscos do empreendimento contratado, ou até mesmo durante a observação de desvios para ajudar a nortear as ações. 
Como Obras de Montagens apresentam como característica marcante a rotatividade de mão de obra, o modelo proposto pode retratar essa realidade. Nas simulações efetuadas, utilizaramse dados reais, que foram inseridos e alterados conforme a evolução do trabalho, conforme se observa nos projetos reais, como a taxa de aprendizado esperada, a rotatividade mão de obra, e a produtividade.

A partir dos resultados obtidos, fica evidente que ao longo do tempo a transferência de conhecimento é um fator extremamente importante, que afeta diretamente o desempenho de uma obra. Portanto, para tomada de decisão gerencial, recomendam-se:

- Domínio do escopo de forma a utilizá-lo como ferramenta de transferência de aprendizado;

- Ter uma política bem elaborada, e ter como indicador gerencial a taxa de rotatividade de mão de obra;

- A manutenção de mão de obra com conhecimento da empresa, e do tipo de escopo a ser realizado.

Um fator importante para utilização do modelo nas decisões gerenciais é também utilizá-lo de forma reversa, simulando com taxas ousadas e ver o resultado sobre a produtividade, podendo assim gerar uma política a longo prazo, com foco na melhoria de resultados.

Como uma obra ou projeto ele não tem limitações a não ser ele mesmo. Assim, seria interessante utilizar o modelo sobre aprendizado, para se estudar os limites da própria empresa, quanto a mão de obra, com foco nos resultados financeiros.

O modelo apresentado mostra vários pontos de melhoria, podendo este ter outras variáveis incluídas que interferem no desempenho da mão de obra como por exemplo remuneração por resultados, horas prêmio, folga por meta cumprida, tornando-se uma excelente ferramenta estratégica gerencial dando a possibilidade de ajustar e determinar várias simulações de desempenho.

Outra sugestão para ampliar este estudo, seria modificar o modelo com a inclusão da variável equipamentos, que também é um importante fator de melhoria de desempenho, tanto da mão de obra como da obra como um todo.

Este modelo também pode ser melhorado com a redução de fronteiras tornando-o mais prático e fácil de utilização, tornando uma ferramenta mais simples de simulação sendo capaz de em qualquer momento um gestor efetuar simulações tanto com a variável mão de obra $\mathrm{x}$ tempo, como mão de obra x custos. 
Uma observação importante que este modelo pode agregar em muito dentro de um planejamento estratégico da empresa como ferramenta auxiliar de comportamento de seu desempenho ao longo do tempo como um todo, como por exemplo uma estratégia de manutenção de um quadro fixo de funcionários, com a análise da curva de aprendizado x produtividade, pode ser ter conclusões sobre a viabilidade financeira sobre este aspecto, chagando a conclusões positivas ou não.

Os resultados deste estudo são válidos em unção às comparações históricas que foram possíveis devido ao conhecimento do autor sobre dados de empreendimentos da empresa estudada. Esta consolidação se faz importante visto que para o estabelecimento das taxas, são necessários dados reais para o perfeito delineamento dos resultados.

\section{Referências}

Almeida, J. (2009) Tecnologias da Montagem Eletromecânica. FURG-CTI. Rio Grande.

Andrade, M. R. (2011) Produtividade na indústria brasileira entre 1990 e 2002: comparação entre indústrias de processo e de montagem. Dissertação - Programa de Pós-Graduação em Engenharia de Produção da Universidade Federal de São Carlos. São Paulo.

Argote, L.; Epple, D. (1990) Learning Curves in Manufacturing. Science. Vol. 247, 920924 p. Washington.

Badiru, A. B. (1991). Manufacturing cost estimation: A multivariatelearning curve approach. Journal of Manufacturing Systems, v.10, No. 6, p. 431-441.

Baitello, A. (2012). Avaliação do aprendizado na produtividade de um estaleiro: uma abordagem através da dinâmica de sistemas. 2012. 128 f. Dissertação - Programa de Engenharia Naval e Oceânica, Escola Politécnica da Universidade de São Paulo, São Paulo.

Costas, R. (2014). Entenda por que a produtividade no Brasil não cresce. São Paulo. BBC Brasil. Disponível em: <http://www.bbc.co.uk/portuguese/noticias/2014/05/140519_produtividade_porque_ru $>$. Acesso em 29 de novembro de 2016.

De Negrini, F.; Cavalcante, L. R. (2015). Produtividade no Brasil: desempenho e determinantes - Determinantes. Vol2, Brasília: IPEIA.

Felizardo, J. M. (2010). Capitalismo, organização do trabalho e tecnologia da Produção e seus impactos na qualificação da força de Trabalho. 26 f.Belo Horizonte. Disponível em: 〈http://www.revistalabor.ufc.br/Artigo/volume3/capitalismo.pdf>. Acessado em: 29 de novembro de 2016.

Fernandes, P. S. T. (2005). Montagens Industriais: Planejamento, Execução e Controle. São Paulo: Artliber Editora.

Ferreira, B. G. C. (2016). Um modelo de orçamento de projetos na área de montagem industrial por meio de dinâmica de sistemas. 2016. 141 f.. Dissertação - Programa de Mestrado da Faculdade Ietec. Belo Horizonte. 
Galeano, E.; Wanderley L. A. (2014). Produtividade industrial do trabalho e intensidade tecnológica nas regiões do brasil: uma análise regional e setorial para os anos 19962007. 20 f. Rio de Janeiro. Disponível em: <http://www.ipea.gov.br/ppp/index.php/PPP/article/viewFile/370/286>. Acessado em: 29 de novembro de 2016.

Martins, P. G.; Laugeni, F. P. (2005). Administração da Produção. 2 ed. São Paulo: Saraiva. Mussolini, C. C.; Teles V. K. (2010) Infraestrutura e produtividade no Brasil. Revista de Economia Política, v. 30, No. 4. p. 645-662. São Paulo.

Paranhos Filho, M. (2007). Gestão da Produção Industrial. Curitiba: Ibpex.

Pinho, M. O. (2008). Estudo Prospectivo do Setor Siderúrgico. 19 f. Associação Brasileira de Metalurgia e Materiais. Centro de Gestão e Estudos Estratégicos. Brasília, 2008. Disponível

em: <http://www.abmbrasil.com.br/epss/arquivos/documentos/2011_4_19_10_34_48_875 97.pdf $>$. Acessado em: 07 de fevereiro de 2017.

Senge, P. (2009). The fifth discipline: The artandpracticeofthelearningorganization - A conversationwith Peter Senge.Inovation Associates Â' LeadershipandMasteryProgram. PublishedbyDoubleday. New York.. 